\title{
1 Alongshore variation of aeolian sediment transport on a beach, under offshore
}

2 winds

4 Kevin Lynch ${ }^{1}$, Irene Delgado-Fernandez ${ }^{2}$, Derek W.T. Jackson ${ }^{2}$, Andrew J. Cooper ${ }^{2}$, $5 \quad$ Andreas C.W. Baas ${ }^{3}$, Meiring Beyers ${ }^{4}$

6

$7 \quad{ }^{1}$ School of Geography and Archaeology, National University of Ireland Galway, 8 Ireland

$9 \quad{ }^{2}$ Centre for Coastal \& Marine Research, School of Environmental Sciences,

10 University of Ulster, BT52 1SA, Northern Ireland, Ireland

$11{ }^{3}$ Department of Geography, King's College London, Strand, London, England WC2R 12 2LS, UK

$13{ }^{4}$ Klimaat Consulting \& Innovation Inc., Ontario, Canada

15 Abstract

16 Understanding the morphodynamics of beach-dune systems requires knowledge of

17 the spatio-temporal variability of the sediment transport system. It is common in aeolian studies to employ a single transect instrument set up, oriented parallel to the wind direction. This experimental design assumes that there is no significant variation in sediment transport lateral to this direction. A limited number of recent studies into this lateral (or spanwise) variability have revealed substantial differences in transport rates over very short spanwise distances $(<4 \mathrm{~m})$. Research investigating scales of $10 \mathrm{~s}$ of metres is even more limited. This paper examines alongshore

24 variability of aeolian sediment transport at this scale. Data were collected over eight 25 hours during an offshore wind event. Thirteen Jackson traps were deployed, co- 
26 located with three-dimensional ultrasonic anemometers (UAs). The instruments were

27 deployed in a grid covering an area of $55 \mathrm{~m}$ cross shore and $90 \mathrm{~m}$ alongshore. The 28 data were analysed as 5 and 10 min totals, and were mapped for visual assessment 29 of transport patterns. Alongshore variability was quantified using the coefficient of 30 variation (CV). Results confirm identifiable spatio-temporal patterns in sediment 31 transport. The $\mathrm{CV}$ results show alongshore variability ranging from $12 \%$ to $48 \%$, with

32 the lower beach traps showing much greater spatial variation. These values are comparable to earlier studies. The implications of recent research into secondary 34 airflow patterns over dunes are discussed in light of the results presented.

Highlights

- Addresses gap in field - data on alongshore variation in aeolian sediment transport.

- Data collected under offshore wind, adding to rare studies under these conditions.

- Results clearly identify cross- and alongshore spatio-temporal transport patterns.

\section{Keywords}

Aeolian; Beach-dune systems; Sediment transport; Spatio-temporal variation

\section{Introduction}

In beach-dune systems an understanding of the aeolian sediment transport system is critical to understanding the broader morphodynamic functioning of the system.

50 Numerous factors have been shown to affect rates of sediment transport (Sherman, 
51 1995). These include fluid forcing variables, such as wind speed and direction

52 (Arens, 1996, Jackson and McCloskey, 1997 and Leenders et al., 2005), and factors which control the erodibility of the surface (e.g., moisture content (van Dijk et al., 1996 and Wiggs et al., 2004) or grain characteristics (Arens et al., 2002 and Leys and McTainsh, 1996). Because all of these factors can vary over time and space it is to be expected that the resultant sediment transport will also exhibit spatio-temporal variability. Cross shore variability has been identified by many studies (e.g., Bauer et al., 1990), with zonation of the transport patterns apparent in some cases. Most studies, however, assume lateral variability - perpendicular to the airflow direction in the fluid forcing (considered the primary controlling factor) is not significant enough to warrant designing experiments to assess this aspect. This has resulted in the use of single transect lines that are aligned parallel to the airflow direction (e.g., Davidson-Arnott et al., 2008, Hesp et al., 2005, Nordstrom et al., 1996 and Walker et al., 2006). This is also the case in many wind tunnel studies, where only one instrument line is common (e.g., Bauer et al., 2004,Butterfield, 1999, Dong et al., 2004 and Rasmussen and Mikkelsen, 1998), in most desert studies (e.g., Baddock et al., 2011, Weaver and Wiggs, 2011 and Wiggs et al., 1996) and in the fluvial literature (Best, 2005). Another likely reason for the use of single transect lines is the common shortage of physical and human resources (Sherman, 1995).

71 Where lateral variability has been assessed it has been found to fluctuate

72 considerably.Gares et al. (1996) investigated alongshore trends in sediment

73 transport during offshore wind events. Alongshore transport rates were assessed in

74 comparison to spatial variations in a number of variables, including moisture,

75 carbonate content, wind speed and sediment size. Wind gustiness (high variability in 
speed and direction) and moisture appeared to contribute more to the variable transport rates than any of the other variables. Nordstrom et al., 2007 and Nordstrom et al., 2006 and Jackson et al. (2006)recorded high spatial variability in sediment transport over a 4 m distance for alongshore and offshore winds in a complex human altered beach-dune system. More recently Ellis et al. (2012) have reported substantial lateral variability in sediment transport rates at two separate field sites. Employing similar spatial $(<4 \mathrm{~m})$ and temporal (3-20 min) scales they demonstrated that lateral variability in sediment transport rates could lead to up to $100 \%$ disparity between predicted and observed transport rates if single point measurements are relied upon.

Recent research on secondary airflow dynamics and the role turbulent structures may play in grain entrainment have highlighted the complex nature of the forcing fluid flow itself. Topographic steering of alongshore winds towards the foredune (Walker et al., 2006), airflow stagnation followed by acceleration up the stoss slope and further steering or flow separation at the crest (Hesp et al., 2005), topographic steering or reversed flow on the lee side of dunes (Lynch et al., 2008, Lynch et al., 2009 and Lynch et al., 2010) have been recorded in coastal dune environments. In theory, the spatio-temporal variations evident in airflow should be reflected in the sediment transport patterns. It is on this premise that Baas and Sherman (2006)investigated the lateral variability of sediment transport using statistical characterization analyses. Their field study found that variability increases with spatial scale, with impact sensors $4 \mathrm{~m}$ apart recording up to $266 \%$ differences in transport rates. These differences occurred under fairly constant wind conditions (within $15^{\circ}$ of array normal). 
100 While Baas and Sherman (2006) targeted an environment where a uniform boundary

101 layer was expected, to date, no studies have been undertaken to incorporate recent

102 advances in our understanding of secondary airflows in controlling lateral variability

103 in sediment transport patterns.

104 The research reported here was designed to investigate if lee side secondary airflow 105 structures that may occur during offshore winds result in alongshore variations in 106 sediment transport on the beach. Delgado-Fernandez et al. (2011) quantified near

107 surface airflow patterns under offshore conditions at the Magilligan Strand, Northern

108 Ireland, using quadrant analysis to propose a quantitative model describing airflow

109 reversal, transition and its re-attachment in the lee of a coastal dune. Findings from

110 Delgado-Fernandez et al. (2011) were later used as a basis for Computational Fluid

111 Dynamics (CFD) simulations, with results suggesting the nature of the airflow

112 response in the lee of the dunes was not uniform alongshore (Jackson et al., 2011).

113 In simulations, using a detailed digital elevation model of the site incorporating dune

114 crest irregularities and dune lee side complex topography, heterogeneity within the

115 secondary airflow patterns was evident. Zones of enhanced transport potential (i.e.,

116 higher wind speeds close to the surface) were seen to alternate with zones of

117 reduced potential, with spacing in the order of $10-50 \mathrm{~m}$. While Jackson et al.

118 (2011) presented wind simulations in three-dimensions their field airflow data was

119 recorded along a single cross shore transect, making it insufficient for the purpose of

120 investigating alongshore wind patterns in the field.

121 A field experiment was designed to assess spatio-temporal patterns of sediment

122 transport and secondary airflow, under offshore winds. This paper reports on the

123 variability of sediment transport on the beach [a companion paper reports the finding 
124 regarding the airflow dynamics, with another companion paper reporting on the role turbulent airflow structures play in the initiation of sediment transport.

126

\section{2. Study site}

128 Magilligan Strand, Northern Ireland was used as a study site (Fig. 1). The beach is 129 oriented along a north west - south east axis and is dominated by prevailing south 130 westerly offshore winds. The foredunes are up to $12 \mathrm{~m}$ in height at the site and are backed by dune ridges of similar height. All ridges are densely vegetated by Ammophila arenaria. The slope of the foredune facing the beach (the lee side

133 under off shore airflow) is abrupt and is thought to enhance airflow separation under 134 certain conditions ( Beyers et al., 2010). The foredune toe section at the site had been accreting for a number of years at the time of the study, with embryo dunes up to $1 \mathrm{~m}$ height in place. The beach is generally planar, and up to $\sim 100 \mathrm{~m}$ wide during spring low tides. Sediments consist predominantly of very well sorted, fine-grained quartz sand, with a mean grain size of $0.17 \mathrm{~mm}$. The beach was relatively free of

139 drift material and vegetation at the time of the experiment. The site was chosen based on previous observations of airflow separation and reversal during offshore winds. Recent research by Lynch et al. (2010) observed that different dune

142 morphologies along Magilligan Strand interacted differently with the flow. Sharp-

143 crested, high dune sections such as the one of the study site resulted in flow

144 separation and reversal while more rounded, shorter dunes along the NW end of the 145 spit resulted in deflection of attached airflows. Numerical simulations using CFD 146 tools by Beyers et al. (2010) and Jackson et al. (2011), and field data presented 147 by Delgado-Fernandez et al. (2011) confirmed the existence of clear patterns of 148 airflow separation and reversal at this particular site. 
150 3. Methods

\subsection{Field measurements}

152 Data were collected over eight hours during an offshore wind event on 26 April 2010.

153 The surface was dry and relatively free of shell lag deposits, algae, and other debris 154 strongly affecting general transport dynamics. Micro topographical features such as 155 ripples developed before and during the experiment (Fig. 2). Thirteen continuously weighing horizontal sediment traps were deployed. The traps are a modified form of

157 the Jackson trap (Jackson, 1996) where the tipping bucket mechanism was removed 158 and the load cell upgraded to hold approximately $3.5 \mathrm{~kg}$ of sand before it required 159 emptying. This greatly reduced data post processing time. The traps were co-located 160 with three-dimensional ultrasonic anemometers (UAs), each placed at a height of $1610.5 \mathrm{~m}$. (Fig. 2). The instruments were deployed in a grid covering an area of $55 \mathrm{~m}$ 162 cross shore and $90 \mathrm{~m}$ alongshore. Cross shore spacing between each pair of 163 instruments was $10 \mathrm{~m}$. Additional traps were deployed along Transect B to give a $1645 \mathrm{~m}$ spacing for this line of instruments. Alongshore spacing of the transects was $16530 \mathrm{~m}$, intended to sample zones of enhanced and reduced potential transport 166 suggested by Jackson et al. (2011). An anemometer (Gill HS-50 model) was also

167 positioned at the foredune crest at a height of $6 \mathrm{~m}$ (18 $\mathrm{m}$ above the beach surface).

168 All instruments were connected to an on-site personal computer and logged 169 simultaneously at $25 \mathrm{~Hz}$. A total of 14 traps were deployed during this run, however, 170 instruments located in position D1 did not perform correctly and hence have been 171 excluded from the analysis. Instrument positions and survey data were gathered with 172 a Trimble 4800 Differential Global Positioning System (DGPS). Topographic 
173 information of the beach surface as used to create a detailed digital elevation model

174 of the study site (Fig. 3).

175 3.2. Analysis methods

176 The trap data were analysed as 5 and $10 \mathrm{~min}$ totals, and were mapped for visual

177 assessment of transport patterns. The co-located anemometer data were used to

178 infer transport direction. Anemometers were oriented in the field in similar directions

179 with respect to North and levelled with respect to the horizontal gravity plane. Each

180 anemometer was sampled at $25 \mathrm{~Hz}$ and provided time series of three components of

181 the wind vector, $u$ (streamwise), $v$ (spanwise), and $w$ (vertical). These were first

182 averaged into 5 and 10 min periods and subsequently used to calculate wind

183 direction $(\alpha)$ and wind speed $(S)$ as:

184

185

$\alpha=180-\operatorname{atan} 2(u, v)$

equation (1)

186

$187 S=\left(u^{2}+v^{2}+w^{2}\right)^{0.5}$

equation (2)

188

189 The sediment transport data were converted to total accumulation in $\mathrm{g} \mathrm{m}^{-2}$ for 10

190 and 5 min periods.

191 In order to compare the results here directly with those of Gares et al.

192 (1996) alongshore variability was quantified for each cross shore beach zone. The

193 range of variation coefficient (RVC) and the coefficient of variation (CV) were

194 calculated for the lower, mid and upper beach. The RVC is obtained by dividing the

195 average value for a set of traps by the minimum and maximum values for that set.

196 The CV is obtained by dividing the standard deviation for a set of traps by the 197 average value for that set. 


\section{4. Results and discussion}

200 Spatio-temporal patterns are evident from a time series plot for the eight-hour period. 201 A distinct clustering of sediment transport is evident in the data over the duration of 202 the event (Fig. 4). System organisation develops quite quickly after the beginning of 203 the transport event and persists, with some variation, until the end of the event.

204 Shore parallel zonation is evident for the upper and mid beach, with the lowest 205 sediment flux on the upper beach (yellow) and the high flux values for the mid beach 206 (pink). The lower beach position, however, ranges from the highest transport rates to 207 the lowest over the course of the event (blue). The spread of the data lines on the 208 plot gives a direct indication of the alongshore variation of transport. Tight clustering 209 on the upper beach (yellow lines) indicates little alongshore variability in the total 210 sediment trapped within this zone; less clustering is apparent on the mid beach (pink 211 lines); while a high degree of variability in sediment transport is evident on the lower 212 beach (blue lines).

213 A quantification of the alongshore variability for the upper, mid and lower beach sets 214 of traps is shown in Fig. 5. Although the sediment transport rate on the mid beach $215\left(2.51 \mathrm{~kg} \mathrm{~m}^{-1} \mathrm{hr}^{-1}\right)$ was twice that of the upper beach $\left(1.23 \mathrm{~kg} \mathrm{~m}^{-1} \mathrm{hr}^{-1}\right)$ the range of 216 variability is quite similar (RVC, respectively of $92-114 \%$ and $84-112 \%$ ). The lower 217 beach on the other hand has a much greater range of variability $(52-165 \%)$, while 218 sediment transport rates are within the range of the other zones $\left(1.74 \mathrm{~kg} \mathrm{~m}^{-1} \mathrm{hr}^{-1}\right)$. 219 The CV results show the contrasting variability more clearly, with upper (12\%) and 220 mid beach (14\%) traps exhibiting similar values and the lower beach traps showing 221 much greater spatial variation (48\%). 


\subsection{Cross shore patterns}

223 The patterns described above are further elucidated by mapping the transport

224 quantities and adding a direction component. A $1 \mathrm{~h}$ subset of data were used from a 225 period when airflow was directly offshore at the crest and of a sufficient speed to 226 enable sediment transport on the beach surface. Transect B was used for this 227 analysis as it had the most instrumentation, thereby giving the most detailed picture 228 of the cross shore sediment transport patterns, and allowing a much clearer 229 differentiation between zones. There are clearly identifiable trends in both magnitude 230 of transport and the direction of movement (Fig. 6). Transport on the lower beach 231 does not exceed $373 \mathrm{~g} \mathrm{~m}^{-2}$ for any 10 -min period and consistently blows offshore 232 (Zone I). The next two traps up the beach collected considerably more sediment 233 ranging from 403 to $997 \mathrm{~g} \mathrm{~m}^{-2}$, with movement fluctuating between obliquely offshore to directly offshore (Zone II). Landward of this a zone of shore parallel sediment transport is evident, with maximum transport of $845 \mathrm{~g} \mathrm{~m}^{-2}$ (Zone III).

236 Transport at the dune toe diminished to range between 113 and $667 \mathrm{~g} \mathrm{~m}^{-2}$, with 237 movement consistently directed onshore (Zone IV). The sediment transport zonation across the beach remains consistent over the one hour period.

\subsection{Alongshore patterns}

240 Alongshore patterns are assessed using the cross shore trends described in the 241 previous section, rather than on a trap by trap basis. As the traps on Transects A, C 242 and $\mathrm{D}$ had a $10 \mathrm{~m}$ spacing only the equivalent traps on Transect B are used for this analysis. The sediment transport on Transect A seems to follow the magnitude and

244 direction patterns of Transect B, with the only deviation being onshore directed 245 transport during the second 10 min period for the mid beach position (Fig. 7). The 246 transport magnitudes of Transect $C$ are less than that of all other lines. The transport 
247 direction on the lower beach is orientated more consistently directly offshore, with

248 the mid beach transport direction orientated alongshore to onshore in comparison to

249 alongshore to offshore for the other mid beach traps. Line D shows the highest

250 transport rates with consistent oblique offshore transport. Considering these data,

251 therefore, it may be said that the cross shore zones - identified in Fig. 6 - are

252 replicated at each position along the beach and do so consistently for the period of

253 the transport event. Where slight alongshore deviations exist they do so in a

254 consistent manner, suggesting there may be a fairly fixed alongshore controlling

255 factor at play. The variability of transport direction alongshore is largest within the

256 mid beach zone, with Transects $A$ and $C$ showing a majority of onshore directed

257 transport and Transects $B$ and D showing offshore directed transport. This also

258 suggests the existence of preferential zones for onshore directed transport that are

259 fairly permanent through time.

260 To assess cross and alongshore patterns further the data from 08:10 to 08:40 were

261 binned at 5 min intervals (Fig. 8). At this time scale the the cross shore zonation for

262 lines B and D again match those at the longer time scale, with the lower and upper

263 beach transport patterns of lines $A$ and $C$ also following the trend. The mid beach

264 traps for lines $\mathrm{A}$ and $\mathrm{C}$ exhibit highly variable transport from one period to the next.

265 The beach sediment transport zonation at this time scale may then be described as:

266 Zone I - lower beach, offshore directed transport of a magnitude less than the mid-

267 beach and greater than the upper beach; Zone II - mid beach, high directional

268 variability and highest transport rates; Zone III - upper beach, onshore directed

269 sediment transport of realtively low magnitude. Alongshore patterns also remain

270 fairly consistent at this time scale. However, as the time scale decreased directional 
271 variability at many of the traps locations increased, especially those within the mid 272 beach zone.

273

\section{5. Results and discussion}

\section{5.1. Alongshore sediment transport complexity}

276 The results presented here show alongshore heterogeneity in sediment transport 277 occurs under offshore winds at this site. The pattern of variation in transport along 278 transects spaced $30 \mathrm{~m}$ apart correspond, at least qualitatively, with the CFD 279 simulation results ofJackson et al. (2011). That is, areas of higher transport 280 (Transects $\mathrm{A}$ and $\mathrm{C}$ ) interspersed alongshore with areas of lower transport 281 (Transects B and D). Interestingly the alongshore zones persisted over the one hour 282 period presented here - this may suggest that there is a controlling factor at play that 283 is orientated along a cross shore plane, or that fixes the forcing airflow in that plane. 284 So, while spatial complexity is evident in the sediment transport data, it is not chaotic 285 and may be described as organised - possibly driven by coherent lee side airflow 286 structures such as roller and helical vortices described by Walker and Nickling 287 (2002). The fact that there is an oblique facet to the transport direction would be better explained if a helical vortex was present. It may be noted, however, that the 289 alongshore component was a small fraction of the sediment being moved on the 290 beach. If there was a more significant amount of sediment moving parallel to the 291 dunes the alongshore variation in transport rates may not have occurred. For 292 example, with significant shore parallel movement Transect $\mathrm{C}$ would be fed by 293 Transect B and might have expected to display similar transport rates, rather than 294 the low relative rates it actually recorded. Similarly there was a large degree of 295 directional variability alongshore suggesting that transport was at some points 
296 directed even in opposite directions within the same zone. For example, the period of 297 time from 8:30 to 8:35 in Fig. 8 shows transport to the west in the upper beach trap 298 (onshore) and the mid beach trap (offshore) along Transect A. Transport is aligned 299 almost cross shore along Transect B, and it changes to the east in Transect $\mathrm{C}$ and 300 D. That is to say, sediment transport was not consistently steered in one direction 301 which suggests that there might be differentiated areas of complex airflow reversal 302 and helical vortices deflected in different directions during perpendicular offshore 303 winds. Although a counter point here is that sand transport may have been quite 304 localised; relatively high mid-to-lower beach rates were not observed feeding the 305 lower beach traps just $5 \mathrm{~m}$ away where the transport rate was on average $36 \%$ of the 306 mid-to-lower beach traps on Transect B (Fig. 6). The interpretations suggested here 307 are based on the assumption that other factors that can have a strong influence on 308 spatio-temporal variations in sediment transport were not significant here. The 309 shoreline during the period of time covered in Fig. 6, Fig. 7 and Fig. 8 was at least $31030 \mathrm{~m}$ apart from the last trap (low tide) and the beach surface was dry and free of 311 debris.

\section{5.2. Comparison with other studies}

313 Gares et al. (1996) is the only study that had similar conditions to this one: offshore 314 winds, a $12 \mathrm{~m}$ foredune and a relatively clean, flat beach surface. The positioning of 315 their $30 \mathrm{~m}$ trap line is approximatley comparable to the lower beach traps used in this 316 study, while their $55 \mathrm{~m}$ trap line would be seaward of this position. The alongshore 317 variability at the $30 \mathrm{~m}$ line (Run 10 ) had a range of variation from $39 \%$ to $175 \%$ 318 (RVC; or CV 43\%, calculated from values in Gares Fig. 8) compared to $52 \%$ to $165 \%$ 319 (CV 48\%) for this study. Seaward of this position the range of variation reduced 320 considerability to $78 \%$ to $119 \%$ (RVC; CV $17 \%$ ), which would be expected as the 
321 topogaphical influence of the foredune recedes and a new internal boundary layer

322 becomes established. In contrast, the results of this paper may be considered

323 unexpected. The quantitative description of the airflow patterns (Delgado-Fernandez

324 et al. companion paper) locates the mid and upper beach traps in highly turbulent

325 areas (reversal; transition; re-attachment zones) where higher relative variations in

326 wind speed and direction were recorded in comparison to the lower beach trap

327 position, where a new inner boundary layer had begun to form. The alongshore

328 variations in sediment transport do not match this pattern. The alongshore variation

329 between traps located in the relatively more turbulent areas show low CV values of

$33012 \%$ for the upper beach and $14 \%$ for the mid beach (and as stated above $48 \%$ for

331 the lower beach). A possible explanation for this unexpected finding is that

332 alongshore each set of traps - with little variability - is in the same cross shore zone,

333 while the set of traps with high variability are in fact in different cross shore zones. In

334 other words, all the upper beach traps are in the reversal cell, all the mid beach traps

335 are in the transition/re-attachment zone, while for the lower beach traps some may

336 still be in the transition/re-attachment zone, with others in the newly forming inner

337 boundary layer. This assumes that there is a characteristic magnitude-distribution

338 sediment transport signal for each cross shore zone.

339 Alongshore variation values reported here are comparable to other studies that have

340 investigated variations in transport perpendicular to the airflow direction. Nordstrom

341 et al. (2006) recorded a value of $12 \%$ variability (CV) for 3 traps on the foreshore

342 over a distance $20 \mathrm{~m}$ alongshore, under offshore winds for a $2 \mathrm{~h}$ period (The CV

343 value is calculated from Table 2). Over shorter scales Baas and Sherman (2006),

344 using 35 safires over $4 \mathrm{~m}$ for $2 \mathrm{~min}$, found CV $48 \%$ in alongshore (spanwise)

345 variation. Also over 4 mJackson et al. (2006) utilised five traps over a periods from 
$34625 \mathrm{~min}$ to $1 \mathrm{~h}$ and recorded spatial variation perpendicular to the airflow of between

$34733 \%$ and $91 \%$.

348 It is significant that the results presented here show patterns evident in the sediment

349 transport system persist over time for a relatively long record ( $8 \mathrm{~h}$ ) with relatively long

350 (10 min) averaging intervals (Fig. 4, Fig. 6, Fig. 7 and Fig. 8). Most studies on

351 variability in sediment transport investigate the (apparent) randomness of the

352 system, with fluctuations in the transport expected to diminish as longer averaging

353 intervals are used. This is not the case in the results presented here, suggesting that

354 the secondary airflow patterns (thought to be controlled by topographic variations at

355 the fordune crest) impart a structure on the sediment transport patterns; reflected in

356 alongshore and cross shore variability.

\section{5.3. Aeolian sediment transport and beach-dune dynamics}

358 Despite the alongshore variability in sediment transport patterns it is worth noting 359 that the average rate of transport on the upper beach was $1.23 \mathrm{~kg} \mathrm{~m}^{-1} \mathrm{hr}^{-1}$ and was 360 directed onshore, aiding in dune maintanance during offshore airflow. This finding, in 361 addition to the alongshore variability in transport shown here, has significant 362 implications for the modelling of beach-dune morphodynamics. In aeolian dune 363 settings secondary airflow patterns are an inherent component. These airflows have 364 been shown here and elsewhere to influence the sediment transport system, 365 therefore models based on primary (regional) data alone will be fundamentally 366 flawed. When investigating offshore airflows the use of a single cross shore transect 367 may misrepresent the overall sediment transport budget depending on placement, 368 even at an averaging time scale in the order of $10 \mathrm{~min}$. 


\section{Conclusions}

371 An understanding of secondary airflow patterns and the three dimensional nature of

372 sediment transport is critical to understanding the morphodynamics of beach-dune

373 systems. This study has documented various aspects of the sediment transport

374 system on a sandy beach under offshore winds.

375 Quantifiable spatio-temporal variability in aeolian sediment transport is evident 376 during offshore wind events. In a cross shore direction, zonation may be identified

377 from transport magnitude and direction characteristics. These zones of sediment 378 transport may persist over time. The cross shore trends, although consistent over 379 time, have been shown here to vary according to their alongshore position. These 380 results highlight the important three-dimensional nature of aeolian sediment transport 381 in complex beach-dune systems and the need to incorporate an alongshore (or 382 lateral) dimension in any attempts to model this environment.

384 Acknowledgements

385 We wish to thank field technicians Robert Stewart, Sam Smyth and Peter Devlin for 386 their GPS field surveying efforts. Thanks are also extended to Colin Anderson 387 (electronics workshop) and Nigel Macauley (mechanical workshop) whose expertise 388 was essential in the construction of the data interface system and instrument rig, 389 respectively. Thomas Smyth provided invaluable assistance in the field. Access to 390 the field site was kindly provided by Defence Estates, UK. This work is funded 391 through the UK Natural Environment Research Council grant NE/F019483/1. 392

\section{References}


Arens, S.M., 1996. Rates of aeolian transport on a beach in a temperate humid climate. Geomorphology, 17 (1996), pp. 3-18

397 Arens, S.M., van Boxel, J.H., Abuodha, J.O.Z., 2002. Changes in grain size of sand in transport over a foredune. Earth Surf. Proc. Land., 27 (2002), pp. 11631175

400

Baas, A.C.W., Sherman, D.J., 2006. Spatiotemporal variability of aeolian sand 401 transport in a coastal dune environment. J. Coastal Res., 22 (2006), pp.

402 $1198-1205$

403

Baddock, M.C., Wiggs, G.F.S., Livingstone, I., 2011. A field study of mean and 404 turbulent flow characteristics upwind, over and downwind of barchan dunes. 405 Earth Surf. Proc. Land., 36 (2011), pp. 1435-1448

406 Bauer, B.O., Houser, C.A., Nickling, W.G.,. Analysis of velocity profile measurements 407 from wind-tunnel experiments with saltation. Geomorphology, 59 (2004), pp.

408 $81-98$

Bauer, B.O., Sherman, D.J., Nordstrom, K.F., Gares, P.A., 1990. Aeolian transport measurement across a beach and dune at Castroville, California. K.F. Nordstrom, N.P. Psuty, R.W.G. Carter (Eds.), Coastal Dunes: Form and Process, John Wiley, Chichester (1990), pp. 39-55

413 Best, J., 2005. The fluid dynamics of river dunes: A review and some future research directions. J. Geophys. Res. Earth Surf., 110 (2) (2005), pp. 2-5

415 Beyers, J.H.M., Jackson, D.W.T., Lynch, K., Cooper, J.A.G., Baas, A.C.W., Delgado416 Fernandez, I., Pierre-Olivier, D., 2010. Field testing and CFD LES simulation of offshore wind flows over coastal dune terrain in Northern Ireland, Fifth International Symposium on Computational Wind Engineering (CWE2010). North Carolina, US (2010) 
420 Butterfield, G.R., 1999. Near-bed mass flux profiles in aeolian sand transport: highresolution measurements in a wind tunnel. Earth Surf. Proc. Land., 24 (1999), pp. 393-412

Davidson-Arnott, R.G.D., Yang, Y., Ollerhead, J., Hesp, P.A., Walker, I.J., 2008. The 424 425 effects of surface moisture on aeolian sediment transport threshold and mass flux on a beach. Earth Surf. Proc. Land., 33 (2008), pp. 55-74

Delgado-Fernandez, I., Jackson, D.W.T., Beyers, J.H.M., Lynch, K., Cooper, J.A.G., 427 Baas, A.C.W., 2011. Re-attachment zone characterisation under offshore 428 winds blowing over complex foredune topography. J. Coastal Res., 1 (2011), pp. 273-277

Dong, Z.,, Wang, H., Liu, X., Wang, X., 2004. The blown sand flux over a sandy 431 surface. a wind tunnel investigation on the fetch effect. Geomorphology, 57 432 (2004), pp. 117-127

433 Ellis, J.T., Sherman, D.J., Farrell, E.J., Li, B., 2012. Temporal and spatial variability 434 435 of aeolian sand transport: implications for field measurements. Aeolian Res., 3 (2012), pp. 379-387

Gares, P.A., DavidsonArnott, R.G.D., Bauer, B.O., Sherman, D.J., Carter,, R.W.G., 437 Jackson, D.W.T., Nordstrom, K.F., 1996. Alongshore variations in aeolian sediment transport: Carrick Finn Strand, Ireland. J. Coastal Res., 12 (1996), pp. 673-682

440 Hesp, P.A., Davidson-Arnott, R.G.D., Walker, I.J., Ollerhead, J., 2005. Flow dynamics over a foredune at Prince Edward Island, Canada. Geomorphology, 65 (2005), pp. 71-84

443 Jackson D.W.T.,1996. A new, instantaneous aeolian sand trap design for field use.

444 Sedimentology, 43 (1996), pp. 791-796 
445 Jackson, D.W.T., Beyers, J.H.M., Lynch, K., Cooper, J.A.G., Baas, A.C.W., Delgado$446 \quad$ Fernandez, I., 2011. Investigation of three-dimensional wind flow behaviour over coastal dune morphology under offshore winds using computational fluid dynamics (CFD) and ultrasonic anemometry. Earth Surf. Processes Landforms, 36 (2011), pp. 1113-1124

Jackson, D.W.T., McCloskey, J., 1997. Preliminary results from a field investigation of aeolian sand transport using high resolution wind and transport measurements. Geophys. Res. Lett., 24 (1997), pp. 163-166

Jackson, N.L., Sherman, D.J., Hesp, P.A., Klein, A.H.F., Ballasteros, F., Nordstrom, 454 K.F., 2006. Small-scale spatial variations in aeolian sediment transport on a fine-sand beach. J. Coastal Res., 1 (2006), pp. 379-383

Leenders, J.K., van Boxel, J.H., Sterk, G., 2005. Wind forces and related saltation transport. Geomorphology, 71 (2005), pp. 357-372

Leys, J.F., McTainsh, G.H., 1996. Sediment fluxes and particle grain-size characteristics of wind-eroded sediments in southeastern Australia. Earth Surf. Proc. Land., 21 (1996), pp. 661-671

Lynch, K., Jackson, D.W.T., Cooper, J.A.G., 2008. Aeolian fetch distance and 462 secondary airflow effects: the influence of micro-scale variables on mesoscale foredune development. Earth Surf. Proc. Land., 33 (2008), pp. 9911005

Lynch, K., Jackson, D.W.T., Cooper, J.A.G., 2009. Foredune accretion under 466 offshore winds. Geomorphology, 105 (2009), pp. 139-146

467 Lynch, K., Jackson, D.W.T., Cooper, J.A.G., 2010. Coastal foredune topography as 468 a control on secondary airflow regimes under offshore winds. Earth Surf. Proc. Land., 35 (2010), pp. 344-353 
470 Nordstrom, K.F., Bauer, B.O., DavidsonArnott, R.G.D., Gares, P.A., Carter, R.W.G., 471 Jackson, D.W.T., Sherman, D.J., 1996. Offshore aeolian transport across a beach: Carrick Finn Strand, Ireland. J. Coastal Res., 12 (1996), pp. 664-672

473 Nordstrom, K.F., Jackson, N.L., Hartman, J.M., Wong, M., 2007. Aeolian sediment 474 transport on a human-altered foredune. Earth Surf. Proc. Land., 32 (2007), pp. $102-115$

476 Nordstrom, K.R., Jackson, N.L., Klein, A.H.F., Sherman, D.J., Hesp, P.A., 2006.

477 Offshore aeolian transport across a low foredune on a developed barrier island. J. Coastal Res., 22 (2006), pp. 1260-1267

479 Rasmussen, K.R., Mikkelsen, H.E., 1998. On the efficiency of vertical array aeolian 480 field traps. Sedimentology, 45 (1998), pp. 789-800

481 Sherman, D.J., 1995. Problems of scale in the modeling and interpretation of coastal 482 dunes. Mar. Geol., 124 (1995), pp. 339-349

483 van Dijk, P.M., Stroosnijder, L., de Lima, J., 1996. The influence of rainfall on 484 transport of beach sand by wind. Earth Surf. Proc. Land., 21 (1996), pp. $341-$ 485 352

486 Walker, I.J., Hesp, P.A., Davidson-Arnott, R.G.D., Ollerhead, J., 2006. Topographic 487 steering of alongshore airflow over a vegetated foredune: Greenwich Dunes, Prince Edward Island, Canada. J. Coastal Res., 22 (2006), pp. 1278-1291

489 Walker, I.J., Nickling, W.G., 2002. Dynamics of secondary airflow and sediment 490 transport over and in the lee of transverse dunes. Prog. Phys. Geogr., 26 (2002), pp. 47-75

492 Weaver, C.M., Wiggs, G.F.S., 2011. Field measurements of mean and turbulent 493 airflow over a barchan sand dune. Geomorphology, 128 (2011), pp. 32-41 
494 Wiggs, G.F.S., Baird, A.J., Atherton, R.J., 2004. The dynamic effects of moisture on 495 the entrainment and transport of sand by wind. Geomorphology, 59 (2004), 496 pp. $13-30$

497 Wiggs, G.F.S., Livingstone, I., Warren, A., 1996. The role of streamline curvature in 498 sand dune dynamics: evidence from field and wind tunnel measurements.

499 Geomorphology, 17 (1996), pp. 29-46

500

501 List of figures

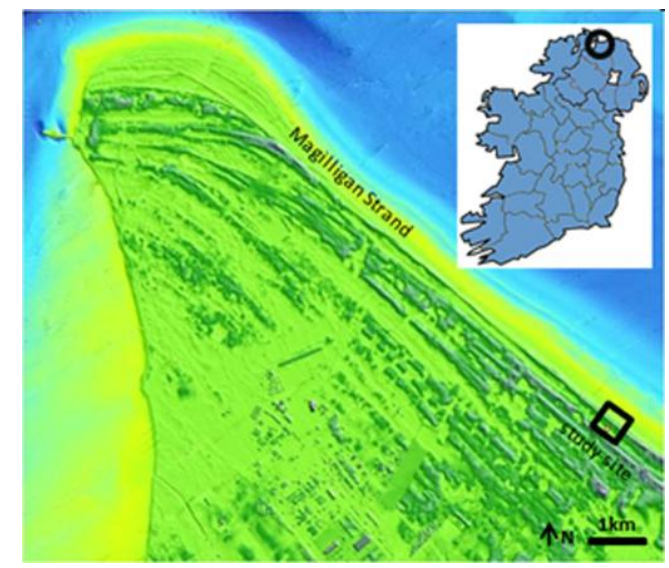

Fig. 1. Location of study site at Magilligan Strand, in Northern Ireland. The area of interest (square) covered a section of approximately $100 \mathrm{~m}$ alongshore. 

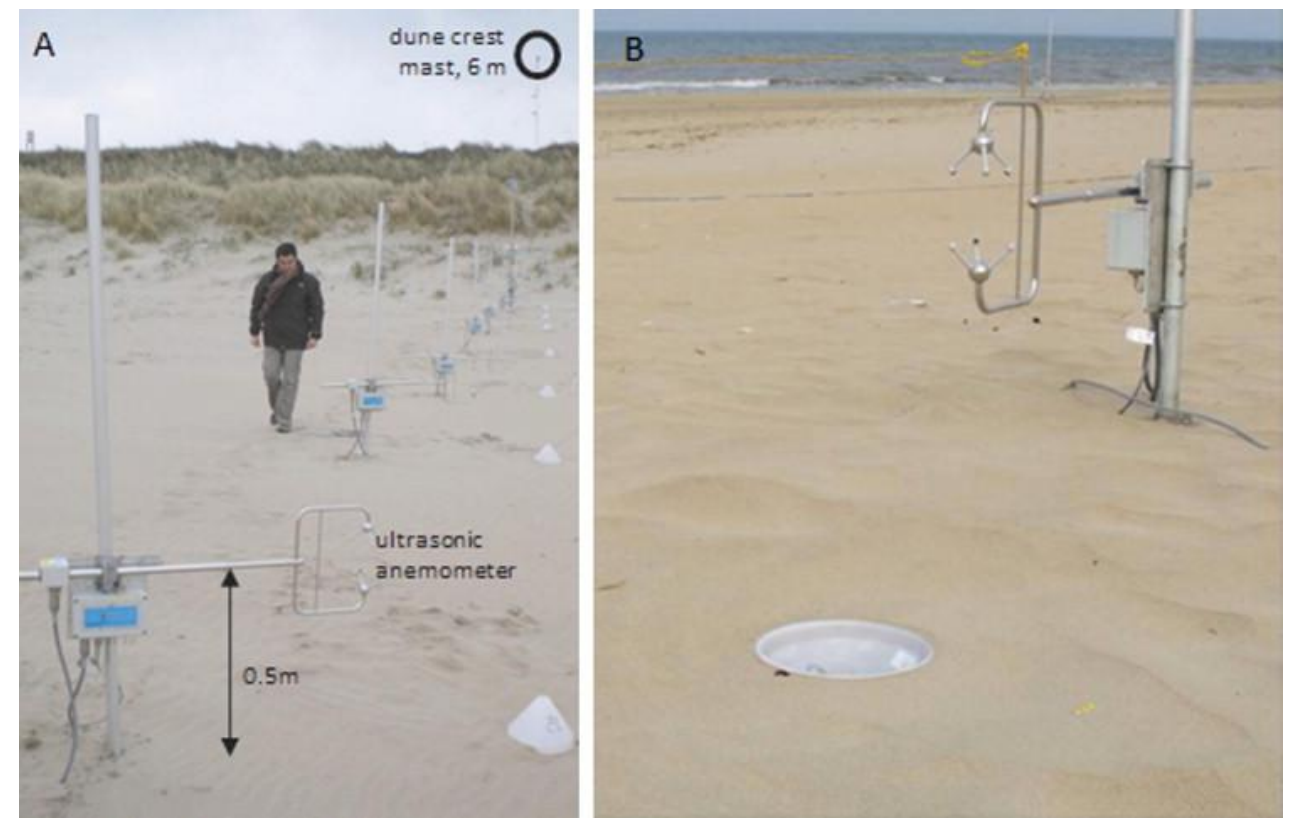

Fig. 2. (A) Close up on station in position B7. Ultrasonic anemometers (UAs) were deployed at $0.5 \mathrm{~m}$ elevation over the beach surface and co-located with a sand trap; (B) Close up on sand trap and UA at position D3 and surface conditions during the run presented here, showing a dry, free of debris beach surface with small aeolian ripples.

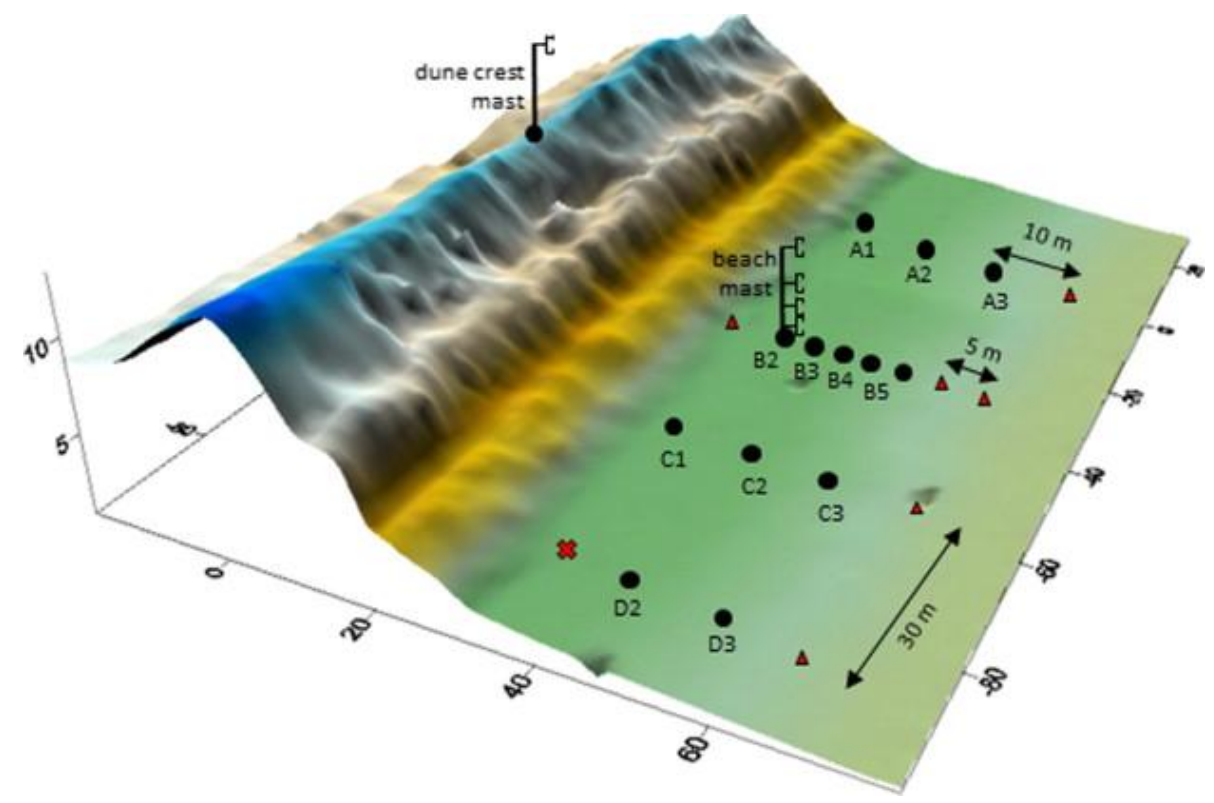

Fig. 3. Topographic surface of the study site and experimental setup. Black dots 
indicate groups of UAs, traps, and safires; triangles indicate only UAs. Instruments located at position D1 (cross) did not function properly during the period of time considered in this paper and hence have been excluded from the analysis. The beach mast contained four UAs at elevations of $0.5,1,2$, and $4 \mathrm{~m}$ over the beach surface (Fig. 4B) and was located at position B2. The dune crest mast contained one UA mounted on a $6 \mathrm{~m}$ high mast on top of the dune crest. The horizontal distance from the dune crest mast to station B1 was approximately $30 \mathrm{~m}$. The vertical axis is exaggerated.

504

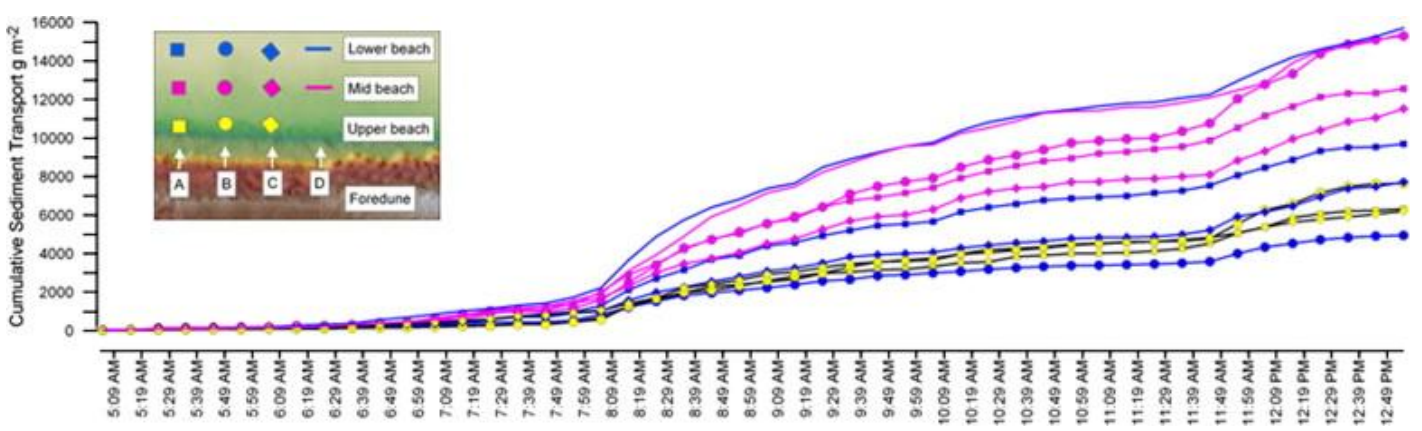

Fig. 4. Sediment accumulation across the beach (10 min accumulations). Trap lines are indicated by symbol shape. Cross-shore position on the beach is indicated by color. It is evident over the course of the event that sediment transport is not uniform across the entire beach. Spatial patterns emerge soon after the beginning of the event. For example, all three upper beach traps (yellow lines) are tightly clustered throughout the time series. Another pattern is that, generally, the mid beach positions (pink line) record the highest transport rates. (For interpretation of the references to colour in this figure legend, the reader is referred to the web version of this article.) 


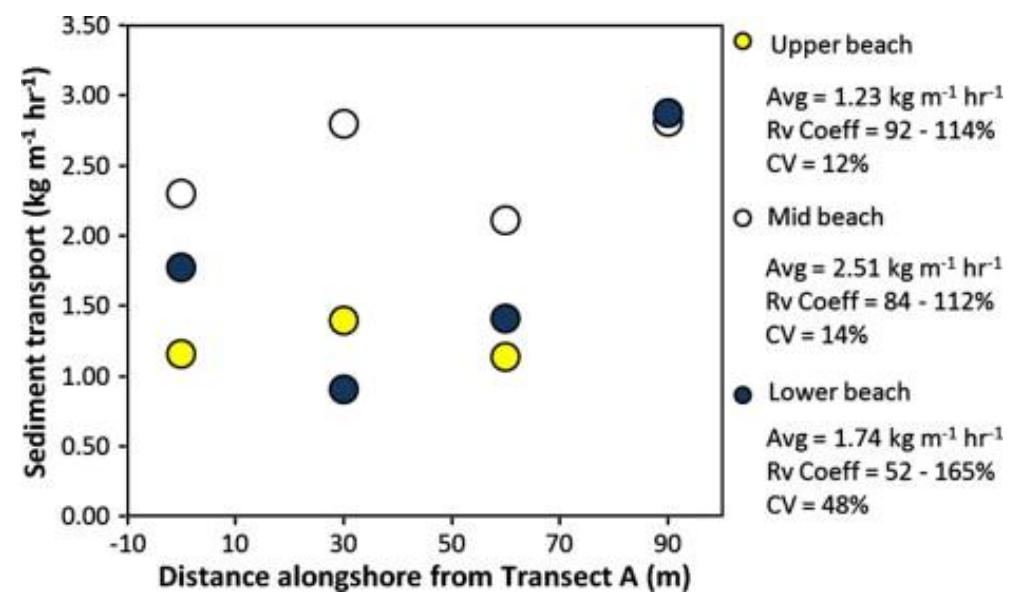

Fig. 5. Quantification of alongshore variability in sediment transport rates. Average (Avg) sediment transport rates on the mid beach were twice that of the upper beach. The range of variability (Rv Coeff) and coefficient of variation (CV) were similar and lower at the upper and mid beach but larger at the lower beach, indicating a much greater alongshore variation within this zone.

506

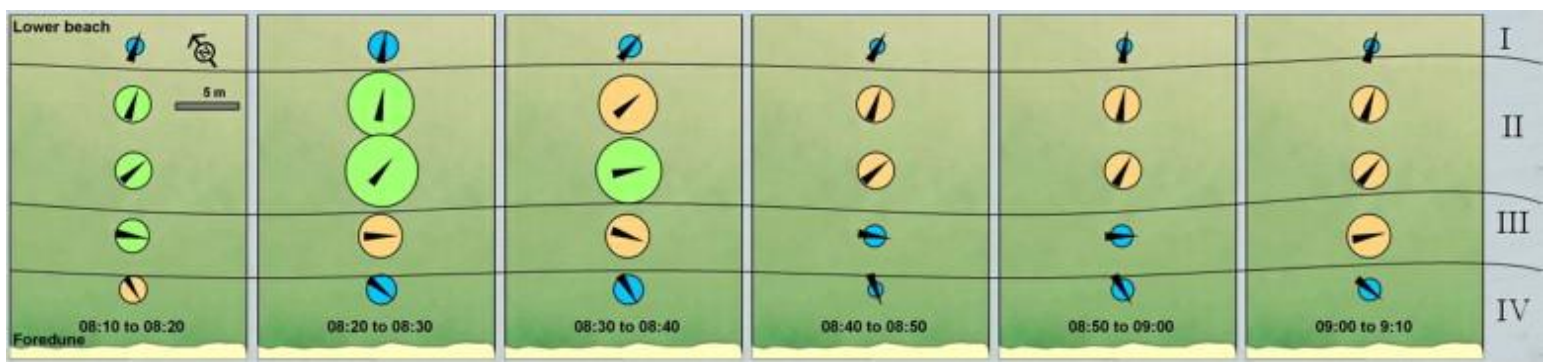

Fig. 6. Cross-shore zonation of sediment transport. Transport data corresponds to 10-min averages over a subset of $1 \mathrm{~h}$ during the transport event. Areas of the beach with consistent sediment transport rates and direction are evident in the data. Zone I - offshore movement of low magnitude. Zone II - highest transport rates on the beach with movement directly or obliquely offshore. Zone III - shore parallel transport of intermediate magnitude. Zone IV - low rates of obliquely onshore sediment transport. 


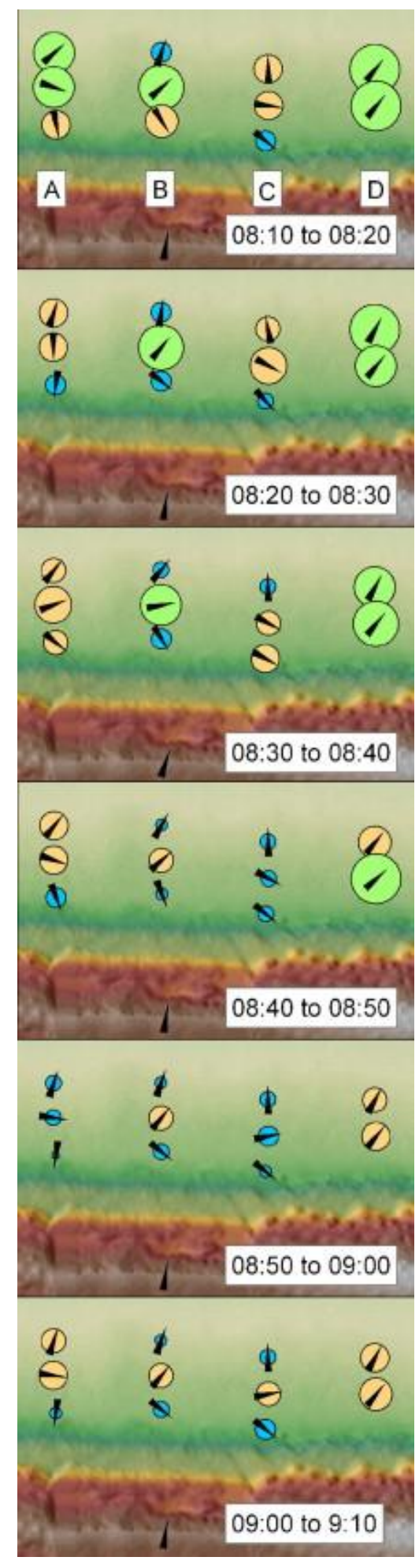

Fig. 7. Alongshore variations in cross-shore zonation of sediment transport.

Deviation in the cross-shore trends identified for line B are evident alongshore, this may be expected - the striking aspect is the cross-shore trends for each line show a considerable degree of consistency (in transport direction and relative magnitude) for 
the hour of data presented here.

508 


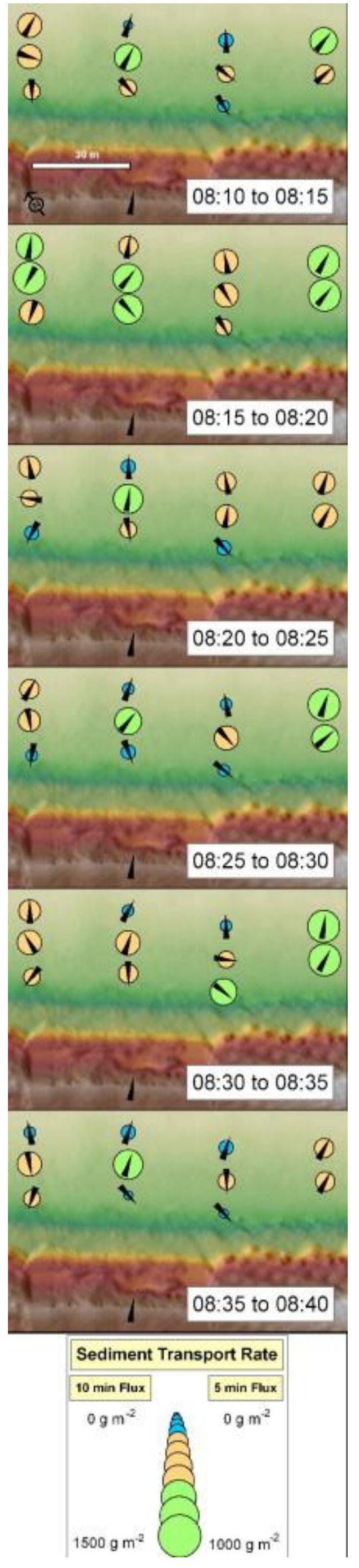


Fig. 8. Five-min intervals of sediment transport. Cross-and alongshore patterns identified at the longer timescale remain identifiable at this scale, suggesting complex yet semi-fixed controlling factors are present. The decrease in time scale increased the complexity of transport patters, suggesting that the wind was steered in opposite directions alongshore within the same zone during certain time intervals (e.g., at the upper beach from 8:35 to 8:40).

509 